\title{
Impact of a Three-year Worksite Wellness Program on Employee Blood Lipid Levels
}

\author{
Kendra Byrd, Kathryn Silliman, and Michelle Neyman Morris \\ California State University, Chico
}

\begin{abstract}
Worksite wellness programs can be used to implement interventions aimed at addressing current rates of obesity and related chronic disease and their associated health care costs. The purpose of this study was to evaluate the impact of a worksite wellness program on blood lipid levels among employees at a rural manufacturing plant in Northern California. Pre to post changes were analyzed using paired sample ttests. Demographic data collected as part of a subsequent nutrition education component of the program indicated that the employees were mostly male (88\%) and Caucasian (71\%), with a mean age of $47 \pm 9$ years. Forty-seven percent of the subjects were overweight and $38 \%$ obese. Following the three-year worksite wellness program, subjects' total cholesterol, LDL-cholesterol, and triglyceride levels decreased, while their HDL-cholesterol levels increased significantly. These results suggest that long-term worksite wellness programs can improve employee health outcomes.
\end{abstract}

(C) 2008 Californian Journal of Health Promotion. All rights reserved.

Keywords: worksite wellness, blood lipids, obesity

\section{Introduction}

The economic costs of obesity are rising steadily, following the pattern of our nation's obesity epidemic (Chenoweth, 2005). In 1990, only $11.6 \%$ of the American population was obese. By 2002, this percentage had increased to $22.1 \%$, doubling the prevalence of obesity in just 12 years (Chenoweth, 2005). Since obesity is associated with an increased risk for chronic diseases such as heart disease, diabetes and cancer, health care costs are on the rise as well. A report prepared for the California Department of Health Services found that in California, the direct and indirect medical care costs from inactivity, overweight and obesity were $\$ 21.7$ billion in the year 2000 and rose to approximately $\$ 28.7$ billion in 2005 (Chenoweth, 2005).

While many health habits are formed in the home, the worksite is a natural place to begin redirecting unhealthy behaviors and potentially reduce health care costs, as most Americans spend a great deal of time at their chosen profession. The Dietary Guidelines for
Americans recommend eating two cups of fruit and two and a half cups of vegetables each day (USDA \& DHHS, 2005). Currently, only about $22 \%$ of Americans eat the recommended servings (Produce for Better Health Foundation, 2002). In addition, sedentary lifestyles prevent many Americans from getting the 10,000 steps per day currently recommended (California Nutrition Network, 2005).

As of 2004, approximately $90 \%$ of companies with 50 or more employees offered worksite wellness programs (Aldana, Merrill, Price, Hardy \& Hager, 2005). In addition, according to a recent survey, $46 \%$ of employers interviewed currently encourage healthy behaviors among their employees by offering financial incentives (Schaeffer, 2008). While methodologies differ, many of the programs have successful approaches in common, such as support from top management, integration of wellness programs with business goals, and sound communication processes (Chapman, 2005). In addition to reducing health care costs, improving employee productivity is another potential benefit of these programs. 
Given that heart disease is the number one cause of death in the United States, worksite wellness programs designed to decrease employees' risk are not uncommon. In 2001, it was estimated that 25 million working Americans had uncontrolled hyperlipidemia (Centers for Disease Control and Prevention, 2005), which may result from a reluctance to get periodic check-ups. In California, $29 \%$ of adults had not had their cholesterol checked within the past five years (Centers for Disease Control and Prevention, 2005). Since hyperlipidemia is a major risk factor for heart disease, wellness programs that target this risk factor have the potential to increase employee productivity and save lives.

Worksite wellness programs, utilizing various methods including the use of peer groups, oneon-one counseling, internet promotions, and self-empowerment components, result in positive behavior change among employees (Aldana et al., 2005; Arneson \& Eckberg, 2005; California Nutrition Network, 2005; Elliot, Goldberg, Duncan, Kuehl, Moe, Breger et al., 2004). Workplace environmental change also leads to positive employee behaviors (Engbers, van Poppel, Paw \& van Mechelen, 2005). In addition to benefiting the employee and their families directly, these programs also benefit the employer. A meta-analysis of 56 peer-reviewed articles found that workplace wellness programs resulted in a $27 \%$ decrease in employee absenteeism, a $26 \%$ decrease in health care costs and a $32 \%$ decrease in Workers Compensation and Disability Claims costs (Chapman, 2004). This is significant given results from a recent survey indicate that employers will spend on average, $\$ 9,144$ on health benefits per employee this year; this represents a $6 \%$ increase since last year (Schaeffer, 2008).

The Stages of Change and Health Belief Models are commonly used when creating health education programs (Prochaska \& Velicer, 1997). The key constructs of the Stages of Change model include: the pre-contemplation stage, in which a person has no plans to change a behavior; the contemplation stage, in which an individual has thoughts about making changes; the preparation/action stage, in which a person is serious about making changes and takes steps to do so; and the maintenance stage, in which the change is being maintained. The Health Belief Model in contrast, examines factors that influence participant health behaviors (Janz \& Becker, 1984). Factors include demographics, socioeconomic status, knowledge about and prior experience with a specific disease, as well as perceived susceptibility or threat of developing a disease. Program development research suggests that perceived susceptibility is a strong predictor for initiating preventive health behaviors (Janz \& Becker, 1984).

The literature suggests that single sessions will not lead to positive changes in health behaviors. Winzenberg, Oldenburg, Frendin, De Wit, Riley and Jones (2006) reported that a four session, small group patient education program was effective at increasing bone mineral density, physical activity and calcium intake in premenopausal women, and Kristal, Glanz, Tilley and Shuhui (2000), reported that five worksite nutrition education sessions offered over one year led to significant improvements in fat, fiber, and fruit and vegetable intakes. In addition to improved dietary intake, improved blood lipid profiles may result from positive behavior changes initiated in the workplace, thus leading to decreased morbidity and mortality among employees and associated health care costs for the employer (Chapman, 2004).

Evaluations of worksite wellness programs have led to mixed results regarding their impact on blood lipid profiles (Braeckman, De Bacquer, Maes, De Backer, 1999; Elliot et al., 2004). Some studies have reported that a short six month nutrition education intervention may be a sufficient amount of time to improve cholesterol levels however, only sustained changes will confer long-term benefits (Elliot et al., 2004; Aldana, Greenlaw, Diehl, Salberg, Merrill \& Ohmine, 2005). Takashi and Yamauchi (2001) reported that a worksite wellness program with an emphasis on physical activity and nutrition, improved lipid levels and maintained these reductions even 18 months post-intervention.

The comprehensive worksite wellness program evaluated in the current study was established in 
2001 between a rural manufacturing plant in Northern California and a local hospital's occupational health center. The purpose of this study was to evaluate the impact of the threeyear worksite wellness program on employee blood lipid profiles.

\section{Methods}

\section{Participants}

Subjects included a non-random sample of employees at a rural manufacturing company in Northern California who participated in the comprehensive worksite wellness program. Participation in the worksite wellness program was encouraged through the use of employer instituted 'profit-sharing' in which employees were monetarily compensated based on the events they participated in, and through announcements of wellness events made at mandatory staff safety meetings. The employer utilized the services and personnel of a partnering local hospital's occupational health center, such as exercise physiologists, phlebotomists and interns thus providing their employees with many health services at a free or greatly reduced cost.

The worksite wellness program activities offered beginning in January 2002 included annual body fat testing and fitness screening, a coping with stress event, and a Step to be Fit program in which employees were given pedometers to track their daily steps. Emphasizing individual accountability, employees signed a 'Commit to be Fit' pledge card, committing to measurably increase their fitness within 90 days. Feedback was provided to employees following the annual body fat testing and fitness screenings. In addition, licensed phlebotomists collected fasting blood samples on an annual basis for blood lipid analyses. Blood lipid profiles were recorded at the local hospital's occupational health center and employees received a copy of their results, which was evaluated by a physician. While the wellness program began providing employees with their blood profiles beginning in 2002, very few employees took advantage of this service the first time it was offered. Therefore, for the purpose of this study, lipid values from 2003 are considered the baseline values. For the blood lipid analyses, study subjects included any employee who had their blood drawn for a lipid panel in 2003 and $2005(n=60)$. Given restrictions on protected patient health information data, demographic or other identifying information was removed from the blood lipid data prior to our analyses.

Many of the program activities offered between 2002 and 2005 were based on the Stages of Change and Health Belief Models and provided data that contributed to a comprehensive wellness profile presented to each employee in the last quarter of 2005. The profile provided detailed information regarding employee physical, mental and environmental health and included recommendations for improving their health status. For example, if an employee's low density lipoprotein (LDL) cholesterol was not in the desirable range, recommendations such as limiting fat intake, especially animal or saturated fat, and eating high fiber foods such as oatmeal, brown rice, fruits, vegetables and legumes, were provided. Over the three-year period, a registered dietitian made one nutrition presentation in 2003 on the topic of how to eat healthy during a twelve-hour shift. This led to the request for a subsequent nutrition education program component, beginning in January 2006, after the second lipid profile analyzed here was obtained. Evaluation results for the nutrition education program are reported elsewhere. Prior to the nutrition education program, informed consent was obtained and a survey including demographic questions was administered. This survey was used in order to generate a demographic profile of employees participating in the worksite wellness program in January 2006, given that demographic data for the 60 subjects for whom blood lipid data are reported here was not available.

\section{Survey Instrument}

The non-random sample of subjects who completed the survey during staff safety meetings in January 2006 was recruited via newsletter distribution and flyer postings throughout the worksite. The survey gathered demographic data and self reported height and weight from which body mass index (BMI) was calculated. The California State University, 
Chico Human Subjects Committee approved all study procedures.

\section{Statistical Analyses}

Data were analyzed using SPSS software version 13.0 (2005, SPSS Inc., Chicago, IL). Descriptive statistics were used to describe subject demographics, and matched paired ttests were used to make blood lipid comparisons among employees pre and post program.

\section{Results}

One hundred ninety nine subjects completed the survey prior to the nutrition education component offered in January 2006. The average age of the subjects was $47 \pm 9$ years and the majority was male (88\%) and Caucasian (71\%) (Table 1). In addition, many employees reported earning between $\$ 50,000$ and $\$ 75,000$ annually (45\%) and living with both a significant other and children (50\%). Based on self-reported height and weight, BMI was calculated and $47 \%$ of the subjects were classified as overweight and $38 \%$ as obese.

In 2003 and 2005, 60 employees had their blood drawn for a lipid panel (Table 2).

Table 2

Pre- to post-subject blood lipid levels $(n=60)$

\begin{tabular}{|l|l|l|l|}
\hline \multicolumn{1}{|c|}{ Blood lipid } & \multicolumn{1}{c|}{$\begin{array}{c}\text { Pre } \\
(\text { Mean } \pm \text { SD) }\end{array}$} & \multicolumn{1}{c|}{$\begin{array}{c}\text { Post } \\
(\text { Mean } \pm \text { SD) }\end{array}$} & $\begin{array}{c}\text { Change } \\
(\text { Mean } \pm \text { SD) }\end{array}$ \\
\hline Total Cholesterol $(\mathrm{mg} / \mathrm{dl})^{*}$ & $199 \pm 31$ & $188 \pm 34$ & $-11 \pm 32$ \\
\hline LDL Cholesterol (mg/dl)**a & $120 \pm 29$ & $109 \pm 29$ & $-11 \pm 25$ \\
\hline HDL Cholesterol(mg/dl)* & $45 \pm 11$ & $48 \pm 11$ & $+3 \pm 7$ \\
\hline Triglycerides $(\mathrm{mg} / \mathrm{dl}) * *$ & $218 \pm 197$ & $154 \pm 102$ & $-64 \pm 176$ \\
\hline
\end{tabular}

${ }^{*} \mathrm{p}<0.05 ;{ }^{*} \mathrm{p}<0.01,{ }^{\mathrm{a}} \mathrm{n}=54$

A paired samples t-test indicated that from 2003 to 2005 there were significant decreases in total cholesterol levels (6\%), LDL-cholesterol levels (9\%), and triglycerides (29\%), while HDLcholesterol levels increased significantly $(7 \%)$.

\section{Discussion}

Worksite wellness programs are garnering attention as an effective means of addressing negative health behaviors and improving health outcomes of employees. Due to the unique partnership between the manufacturing plant and a local hospital's occupational health center, the comprehensive program evaluated here provided employees with many health services at a free or reduced cost over a three year period. While some activities, such as the coping with stress event and the nutrition education session were provided once, others such as the body fat testing and fitness screening were performed on an annual basis with results provided to employees at that time. This consistent feedback as well as the profit sharing incentive program, which paid employees for their participation, potentially increased their interest and commitment to the program. In addition, since this worksite is located in a rural setting, very few employees take the extra time to leave the site for lunch and were therefore, a captive audience at that time as well as during mandatory staff safety meetings when the wellness events were promoted.

Previous studies have identified positive behavior change in employees following worksite wellness interventions. Aldana et al. (2005) reported that employees who participated in two-hour in-person nutrition education sessions held four times per week for four weeks exhibited positive dietary changes. Following the intervention, participants decreased their 
energy intake by 266 calories per day, increased their daily fruit intake by 1.3 servings, and increased their daily vegetable intake by 1.6 servings. In another study, Beresford, Thompson, Feng, Christianson, McLerran, and Patrick (2001) reported that following a twoyear Seattle-based worksite wellness program, employees increased their fruit and vegetable consumption by 0.3 servings per day. The authors suggest that this seemingly low increase for a relatively lengthy intervention may be due to the passive nature of the intervention. Channels to deliver the nutrition messages consisted of posters, brochures, message cards and tip sheets.

Worksite wellness programs also lead to gains in nutrition knowledge by employees. Braeckman et al. (1999) reported that after a three-month nutrition education intervention, employees increased their nutrition knowledge by $44.5 \%$ based on a 10-point questionnaire. Braeckman also reported significant decreases in consumption of total calories and fat following the intervention consisting of posters, flyers, leaflets and educational sessions. Pegus, Bazzarre, Brown \& Menzin (2002) also reported a significant improvement in employee knowledge of hypertension and cardiovascular disease risk factors after participating in the Heart at Work program, which included cardiovascular health messages distributed through e-mails, posters, flyers, and supplemented by brief meetings and health fairs.

Activities associated with the worksite wellness program reported here were based on the Stages of Change model. Kristal et al. (2000) reported that following a worksite wellness program employees were more likely to move into the action or maintenance phases of the Stages of Change Model. Not surprisingly, subjects who were in the action and maintenance phases consistently exhibited the greatest amount of positive dietary change when compared to the other groups.

Consistent with our data, other worksite wellness programs have reported decreases in total blood cholesterol levels, a major risk factor for cardiovascular disease that remains the number one cause of death in the Unites States (Aldana, 2001; Chapman, 2004; Takashi and Yamuachi, 2001). The comprehensive worksite wellness program described here provided participating employees with a free annual blood lipid analysis, along with other health information to which employees might otherwise not have had access. Many activities consisted of risk factor screening for chronic diseases, thus providing employees with knowledge regarding their personal risk. Creating a convenient means by which all employees can easily determine their current health status has the potential alone to affect change, as stated in the Health Belief Model (Janz \& Becker, 1984). In 2001, 25 million Americans had hyperlipidemia and almost a third of Americans had not had their blood lipid levels checked within the previous five years (Centers for Disease Control and Prevention, 2005). Thus, worksite wellness programs that provide employees with their blood lipid profiles have the potential to positively influence their health behaviors.

Unfortunately, given access restrictions on protected patient health information data, demographic or other identifying information was removed from the blood lipid data prior to our analyses. A general sense of employee characteristics at this rural manufacturing plant can be garnered from demographic data collected from the non-random sample of 199 employees participating in the worksite wellness program in January 2006. Nonetheless, it remains unclear which aspects of the program led to the blood lipid level changes and whether those who were overweight responded differently from other subjects. In addition, the degree to which other factors such as friends, family and the media affected the changes observed over the three years remains unknown. Future studies utilizing a control group and obtaining informed consent to link demographic, anthropometric and other health data to blood lipid data at a similar worksite are warranted. In addition, given the inherent limitations of selfreported height and weight, BMI calculations may lack validity for classifying subjects in the current study as underweight, normal or overweight status. However, given that $85 \%$ of the subjects were classified as overweight or 
obese, which is higher than the national percentage, continued intervention among this population seems prudent. Finally, this study was conducted at a rural manufacturing worksite and therefore, the results cannot be generalized to urban settings.

Even with these limitations, evaluation of this comprehensive, three-year worksite wellness program at a rural manufacturing company suggests that it had a positive impact on employee blood lipid profiles. These results are consistent with the literature suggesting that employer sponsored worksite wellness programs are an effective means of promoting positive behavior change and improved health outcomes.
Additional worksite wellness interventions utilizing control groups and designed to determine the variables implicated in any health status change should be evaluated for their immediate and long-term effectiveness.

\section{Acknowledgements}

The authors wish to acknowledge the employees who participated in this program, members of the Safety Committee, including Marianne Krantz and Lisa Fune, who facilitated the worksite wellness program, the occupational health center staff for assistance with data collection and analyses, and Cindy Wolff and Lisa Mathews for their contributions to this study.

\section{References}

Aldana, S. G. (2001). Financial impact of health promotion programs: A comprehensive review of the literature. American Journal of Health Promotion, 15, 296-320.

Aldana, S. G., Greenlaw, R. L., Diehl, A. H., Salberg, A., Merrill, R. M., Ohmine, S. (2005). The effects of a worksite chronic disease prevention program. The Journal of Environmental and Occupational Medicine, 47, 558-564.

Aldana, S. G., Merrill, R. M., Price, K., Hardy, A., Hager, R. (2005). Financial impact of a comprehensive multisite workplace health promotion. Preventive Medicine, 40, 131-137

Arneson, H., Ekberg, K. (2005). Evaluation of empowerment processed in a workplace health promotion intervention based on learning in Sweden. Health Promotion International, 20, 351-359.

Beresford, S. A., Thompson, B., Feng, Z., Christianson, A., McLerran, D., Patrick, D. L. (2001). Seattle Five-a-day worksite program to increase fruit and vegetable consumption. Preventive Medicine, 32, 320-328.

Braeckman, L., De Bacquer, D., Maes, L., De Backer, G. (1999). Effect of a low-intensity worksite based nutrition intervention. Occupational Medicine, 49, 549-555.

California Nutrition Network. (2005). Workplace Nutrition and Physical Activity: An overview of the facts, case studies, and information resources. 1(1):1-11. Retrieved September 5, 2008, from http://www.cdph.ca.gov/programs/CPNS/Documents/Worksite/CPNSFADWorksiteBrieffinal.pdf

Centers for Disease Control and Prevention. (2008). Centers for Disease Control and Prevention home page. Retrieved August 27, 2008, from http://www.cdc.gov

Chapman, L. (2005). Expert opinions on "best practices" in worksite health promotion (WHP). The Art of Health Promotion, 6, 1-10.

Chapman, L. (2004). Meta-evaluation of worksite health promotion economic return studies. The Art of Health Promotion, 6, 1-6.

Chenoweth, D. (2005). The economic costs of physical activity, obesity, and overweight in California adults: health care, workers' compensation and lost productivity. Topline Report. Retrieved August 27, 2008, from http://www.caphysicalactivity.org

Elliot, D. L., Goldberg, L., Duncan, T. E., Kuehl, K. S., Moe, E. L., Breger, R. S. K., De Francesco, C. L., Ernst, D. B., Stevens, V. J. (2004). The PHLAME firefighter's study: Feasibility and findings. The American Journal of Health Behavior, 28, 13-23.

Engbers, L., van Poppel, M., Paw, C., van Mechelen, W. (2005). Worksite health promotion programs with environmental changes: A systematic review (2005). The American Journal of Preventive Medicine, 29, 61-70. 
Janz, N. K., Becker, M. H. (1984). The health belief model: A decade later. Health Education Quarterly, $11,1-47$.

Kristal, A. R., Glanz, K., Tilley, B. C., Shuhui, L. (2000). Mediating factors in dietary change: Understanding the impact of a worksite nutrition intervention. Health Education and Behavior, 27, 112-125.

Pegus, C., Bazzarre, T., Brown, J. S., Menzin, J. (2002). Effect of the Heart at Work program on awareness of risk factors, self-efficacy and health behaviors. Journal of Occupational Medicine and Environmental Medicine, 44(3), 228-36.

Prochaska, J. O., Velicer, W. F. (1997). The transtheoretical model of health behavior change. American Journal of Health Promotion, 12, 38-48.

Produce for Better Health Foundation. (2002). State of the plate research report 2002. Wilmington, DE: Produce for Better Health Foundation.

Schaeffer, J. (2008). Workplace wellness: Companies make employee health their business. Today's Dietitian, 10(7), 34-37.

Takashi, M., Yamauchi, K. (2001). Evaluation of a multicomponent workplace health promotion program conducted in Japan for improving employees' cardiovascular disease risk factors. Preventive Medicine, 33, 571-577.

U. S. Department of Health and Human Services and the U. S. Department of Agriculture. (2005). Dietary guidelines for Americans (6th ed.). Washington, DC: U. S. Government Printing Office.

Winzenberg, T., Oldenburg, B., Frendin, S., De Wit, L., Riley, M., Jones, G. (2006). The effect on behavior and bone mineral density of individualized bone mineral density feedback and educational interventions in premenopausal women: A randomized trial. BioMed Central Public Health, 6(12), 1-12.

Author Information

Kendra Byrd, MS

Department of Nutrition and Food Sciences

California State University Chico

Chico, CA 95929-0002

Kathryn Silliman, PhD, RD

Department of Nutrition and Food Sciences

California State University Chico

Chico, CA 95929-0002

Ph. 530-898-6245

E-Mail: ksilliman@csuchico.edu

Michelle Neyman Morris, PhD, RD*

Department of Nutrition and Food Sciences

California State University Chico

Chico, CA 95929-0002

Ph. 530-898-4757

Fax.: 530-898-5586

E-Mail: mrmorris@csuchico.edu

* corresponding author 


\section{Appendix A}

Table 1

Characteristics of subjects completing a survey in January $2006(\mathrm{n}=199)$ *

\begin{tabular}{|c|c|c|c|}
\hline Characteristic & Mean \pm SD & $\mathbf{n}$ & $\%$ \\
\hline Age & $47 \pm 9$ & & \\
\hline $20-29$ Years & & 9 & 5 \\
\hline $30-39$ Years & & 30 & 16 \\
\hline $40-50$ Years & & 71 & 37 \\
\hline$>50$ Years & & 82 & 42 \\
\hline \multicolumn{4}{|l|}{ Gender } \\
\hline Male & & 175 & 88 \\
\hline Female & & 24 & 12 \\
\hline \multicolumn{4}{|l|}{ Ethnicity } \\
\hline Hispanic & & 36 & 19 \\
\hline Asian & & 1 & 1 \\
\hline African-American & & 4 & 2 \\
\hline Caucasian & & 136 & 71 \\
\hline Pacific Islander & & 1 & 1 \\
\hline Native American & & 11 & 6 \\
\hline Other & & 2 & 1 \\
\hline \multicolumn{4}{|l|}{ Household Income } \\
\hline$\$ 25,000-49,000$ & & 55 & 29 \\
\hline$\$ 50,000-74,999$ & & 86 & 45 \\
\hline$\$ 75,000-100,000$ & & 35 & 18 \\
\hline$>\$ 100,000$ & & 15 & 8 \\
\hline \multicolumn{4}{|l|}{ Living Situation } \\
\hline Myself & & 25 & 13 \\
\hline Significant Other and Children & & 99 & 50 \\
\hline With Significant Other Only & & 58 & 29 \\
\hline With Children Only & & 10 & 5 \\
\hline With Other Family & & 2 & 1 \\
\hline With Roommate(s) & & 4 & 2 \\
\hline Other & & 1 & 1 \\
\hline Body Mass Index & $30 \pm 5$ & & \\
\hline $18.5-24.9$ & & 29 & 15 \\
\hline $25-29.9$ & & 90 & 47 \\
\hline$\geq 30$ & & 73 & 38 \\
\hline
\end{tabular}

* Sample size for individual characteristics vary due to non-response 